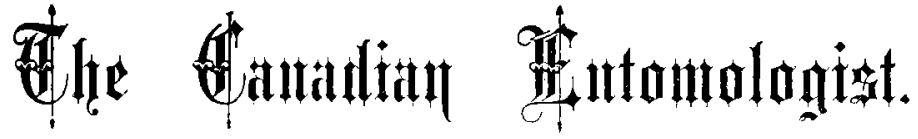

Vol. XXXV. LONDON, FEBRUARY, $1903 . \quad$ No. 2

LIFE-HISTORY AND DESCRIPTION OF THE STRAWBERRY ALEYRODES, ALEYRODES PACKARDI, N. SP.

AUSTIN W. MORRILL, B.S., ENTOMOJ,OGICAL LA BORATORY, MAsSACHUSETTS AGRICULIURAL COLLEGE.

This species has hitherto been considered identical with Aleyrodes vaporariorum, the common greenhouse Aleyrodes of the tomato, cucumber, etc. A critical study of all the stages of both the greenhouse Aleyrodes and the strawberry Aleyrodes, made at the Entomological Laboratory of the Massachusetts Agricultural College, has resulted in finding structural differences between the two species in all the stages, except the egg and adult. These differences may be tabulated as follows:

A. vaporariorum, Westw.

A. Fackardi, n. sp.

\begin{tabular}{|c|c|c|}
\hline Ist instar. & I 8 pairs of marginal spines. & i 6 pairs of marginal spines. \\
\hline 2nd instar & $\begin{array}{l}\text { Ist and } 3 \text { rd pairs of dorsal spines } \\
\text { well developed, though vari. } \\
\text { able in length. }\end{array}$ & $\begin{array}{l}\text { All three pairs of dorsal } \\
\text { spines minute. }\end{array}$ \\
\hline $3^{\text {rd instar. }}$ & $\begin{array}{l}\text { rst and } 3 \text { rd pairs of dorsal spines } \\
\text { well developed, though vari- } \\
\text { able in length. }\end{array}$ & $\begin{array}{l}\text { All three pairs of dorsal } \\
\text { spines minute. }\end{array}$ \\
\hline Pupa. & $\begin{array}{l}\text { 3rd pair of dorsal spines well } \\
\text { developed, though variable in } \\
\text { length. 5-1 } 8 \text { (usually } 8 \text { ) wax } \\
\text { rods arising well up on the dor- } \\
\text { sum in addition to a double } \\
\text { submarginal series of wax rods. }\end{array}$ & $\begin{array}{l}\text { All three pairs of dorsal } \\
\text { spines minute; only a } \\
\text { double submarginal } \\
\text { series of wax rods } \\
\text { present. }\end{array}$ \\
\hline
\end{tabular}

In the above table the spines the cephalic region of the dorsum are designated as the first dorsal pair; those on the sides of the first or third (first instar) abdominal segment as the second dorsal pair; and those which occur one on each side of the vasiform orifice the third dorsal pair. (In the reproduction of the drawings the second pair of dorsal 
spines of the first instar and the first pair of dorsal spines of the pupa were, unfortunately, omitted, see plate 2.)

I have never seen an, Aleyrodes zaporariorum on a strawberry plant out of doors. Specimens of Aleyrodes from Kentucky were recently received through Prof. C. H. Fernald from Prof. Garman on sirawberry leaves, and were found to be identical with the common strawberry Aleyrodes of this locality. Experiments thus far have shown that Aleyrodes vaporariorum when transferred in the first instar to. a strawberry plant will live and develop all the characters of those which feed on the more natural food-plants of the species, while at three different times crawling larva of the strawberry Aleyrodes were transferred to fresh leave: of a growing tomato plant, and all died within a few days, apparently without taking any food. That the Aleyrodes vaporariorum does not naturally feed on the strawberry is shown by the fact that a strawberry plant in a pot remained for over six months in a greenhouse thickly infested with that species and less than half a dozen Aleyrodes matured on its leaves, upon which even the imagoes were very rarely observed resting. It does not seem strange that where the natural food-plants were so thickly infested an egg should occasionally be deposited on other plants.

Incidentally it might be mentioned that in this locality the strawberry Aleyrodes in all its stages, including the egg, averages a little larger in size than the greenhouse Aleyrodes (Aleyrodes vaporariorum).

Egg (Plate 2, Fig. I).

The egg is irregularly oval, with one side more or less flattened; attached to the leaf. by a short stalk, situated on the basal or more broadly-rounded end, usually a little to one side of the centre, toward the more rounded side. When freshly laid, the egg is pale green in colour, with a rounded orange-yellow body within, in a few days changing to a metallic bronze colour. The surface of the egg is unmarked. The length, exclusive of the stalk, is from .23 to $.24 \mathrm{~mm}$.; greatest width, from .08 to $.095 \mathrm{~mm}$. The stalk is from $\mathrm{T} / 8$ to $1 / 4$ the length of the egg.

The length of the egg stage depends upon the weather conditions. Those laid in late fall do not hatch until the following spring, while in the warm summer weather they hatch in thout eight or ten days.

$$
\text { First Instar (Fig. .2). }
$$

In the first instar the general form is oval, the anterior end being the more broadly rounded, the sides of the thoracic region are approximately 
parallel, the abdomen narrowing posteriorly. Immediately after hatching, the body is flat and thin, but just before the first moult it becoines well rounded above. The edge of the body consists of a thin, narrow, marginal rim, at the inner edge of which the body is abruptly thickened. From the under side of this thin rim many minute, glistening granules can be seen. The margin is entire, except for the attachments of the spines. On each side sixteen spines arise on or near the margin of the body. Excepting numbers two, seven and fourteen, counting from the anterior end, these are situated at nearly regular intervals. Number two arises a short distance from the margin on the under side of the body, quite close to the base of one; it is directed downward, curving toward its mate. These spines are best seen from below. Number seven is separated from numbers six and eight by greater intervals than occur between other adjacent spines. Number fourteen arises a little nearer fifteen than thirteen. Number sixteen is very long, varying in length from one-third to one-half the length of the body. Number fourteen is from one-third to one-half the length of sixteen. Numbers one to seven gradually decrease in length. Numbers seven to thirteen are about equal in length, being from one-eighth to one-tenth the length of number sixteen. Number fifteen is slightly longer than thirteen. A marginal secretion of wax appears soon after the young larva settles down. This usually becomes wide enough to cover all but the fifteenth and sixteenth pairs of spines. The segmentation of the abdomen is quite distinct, that of the thorax very indistinct, essentially as in the pupa-case. The vasiform orifice is about as wide as long, its form being somewhat similar to an equilateral triangle with rounded corners. The operculum is subelliptical in outline, flattened on the basal side. The lingula is spatulate in outline, bearing a number of longitudinal rows of minute setæ, and on the caudo-lateral margin two pairs of spines, the posterior pair being the longer. When the lingula is in its natural position, the last-mentioned spines do not reach to the apex of the orifice. The orifice is bounded laterally by chitinous thickenings, which bend toward one another, but do not unite at the posterior end of the orifice. Just inside the apex of the orifice is a small, glistening, crescent-shaped structure, which may be simply a chitinous thickening or an opening in the integument. There are two pairs of reddish-brown eyes, a dorsal and a ventral pair, situated nearly opposite each other, just mesad to the thin marginal rim, and about equidistant from the fourth and fifth marginal spines on their respective 
sides of the body. There are at least two pairs of minute dorsal spines. One pair is situated one on each side of the third abdominal segment; another pair is situated one on each side of and anterior to the operculum. Each of these four spines arises from a minute papilla, which, however, in certain lights, appear like cylindrical cavities or pores. From a study of later instars, it seems possible that another still more minute pair of spines occurs on the cephalic region, but I have not thus far distinguished any such with certainty. The two pairs above located are not difficult to see with a one-sixth inch objective.

On the ventral side of the body the legs, antennæ and mouth-parts are well developed in this instar. Each leg (Fig. 3) consists of a coxa, trochanter, femur, tibia and tarsus. The entire length of the leg when straightened is about one-half the width of the body. The coxæ are short and stout, and near the base of each of the two posterior pairs on the inner side is a spine about twice as long as the diameter of the coxæ. Trochanters short, those of the anterior pair of legs are subcylindrical, about one-third as long as wide. Those of the two posterior pairs of legs appear to be hoof-shaped, and all six trochanters bear a short spine anteriorly. The femur is about twice as long as the coxa and trochanter together, subcylindrical in form, tapering toward its onter end. The tibia is a little longer than the femur, and more slender; in the two posterior pairs of legs, bearing on its outer sile, near its base, a spine as long as the whole tibia itself. This extends obliquely outward, and is usually curved near its tip. Under high-power objectives and with favourable light the tibiæ are seen to bear a number of very minute spines. The tarsus is short and knobbed at the tip, with a stout curved spine onehalf as long as that borne on the tibia, arising on the outer side near its base. Diagonal lines connecting the two anterior pairs of coxæ would intersect at about the centre of the base of a conical papilla-the rostrum -from an opening in the apex of which the mouth setæ protrude. The length of these setæ varies, but when bent backward they usually extend beyond the hind coxæ. In front of these mouth organs is a prostomial plate or shield, subovate in form, the broader end being anterior. It is truncate where it touches the base of the mouth papilla, slightly concave on the sides posteriorly, broadly rounded anteriorly, with two movable papillæ on the anterior margin, each of which bears a long spine, about equal in length to those on the coxre of the two posterior pairs of legs. From the anterior two-thirds of this plate are separated two 
lenticular side pieces by distinct sutures. On the ventral surface of the abdomen, underneath the operculum, is a pair of spines, one on each side, about equal in length to those which arise at the anterior end of the prostomial plate. These spines extend backward, reaching nearly to the caudal margin of the body. The segmentation below is not as distinct as on the dorsal surface. Each antenna arises on a line with the coxæ of the legs of its respective side of the body and about opposite the anterior margin of the prostomial plate. They consist of four segments: the basal segment is short and stout; the second segment is twice as long as the first and more slender, reaching about to the margin of the body when the antenna are directed outward; the third segment is very short and with two or three apical spines; the fourth segment is twice as long as the second, bearing a small spine at about two-thirds the distance toward the tip, and another larger one at the tip.

The colour of the larva is pale green, semitransparent, with two internal orange-yellow bodies of irregular rounded form, situated one on each side in the basal abdominal region.

The length in this instar varies from .29 to $.35 \mathrm{~mm}$.; the greatest width, from . 16 to $.18 \mathrm{~mm}$.

The young larva is capable of crawling as soon as it emerges from the egg. It may crawl a short distance before settling down, or it may settle down quite near its place of birth. It is seldom able to crawl over the larger ribs of a leaflet, being prevented by the thick hairs of the leaf. After settling down it soon loses the use of its legs, and in the course of a day or two the lateral wax secretion appears. The first moult takes place in about five or six days. Lateral growth of the body between the moults is not appreciable, increase in size seeming to result almost entirely from growth in thickness. This is true of all the immature stages. Preliminary to moulting, the skin appears to split around the anterior margin of the body. It is then gradually moved back, aided by up-and-down movements of the abdomen, and usually drops off entirely, sometimes, however, remaining attached to the leaf. Moulting appears to be a slow process, two or three hours or a whole day intervening before the insect is entirely freed from its moulted skin. As each portion of the body becomes free from the skin, it seemingly flows out over the surface of the leaf, and immediately assumes the form and horizontal dimensions which continue throughout the instar. 


\section{Second Instar.}

In this instar the form is more variable than in the first; broadly oval to elliptical, usually with a slight incurving on each side of the thoracic region. When oval, the anterior end is the more broadly rounded. The margin is finely crenulate, but there is no thin marginal rim as in the first instar. Immediately after moulting, the body is flat and thin, but before the next moult it becomes well rounded above. Three pairs of marginal spines are present: the first pair on the latero-cephalic region, one on each side; the second pair on caudo-lateral region, one on each side; and the third pair on the caudal margin. These probably represent spines number one, fourteen and sixteen, respectively, of the first instar. The third pair is a little more than one-tenth the length of the body, the second pair is about one-fourth the length of the third pair, and the first pair is even smaller than the second pair and may be difficult to distinguish. There are three pairs of minute dorsal spines: the first pair is on the cephalic region, one on each side of the middle; the second pair is on the first abdominal segment, one on each side; and the third pair is near the vasiform orifice, one on each side, opposite the operculum. These last are somewhat larger than the first and second pairs, which in some specimens may be difficult to distinguish. They are most readily seen immediately after the insect has moulted. A marginal wax secretion is present as in the first instar, appearing shortly after the moult. The segmentation of the abdomen is fairly distinct in the middle, that of the thorax more obscure. The vasiform orifice is relatively farther forward in this instar than in the preceding one. This is indicated by the comparatively greater distance from the apex of the orifice to the caudal margin of the body and by the fact that the spines on the dorsum, near the orifice, now lie opposite the operculum, instead of anterior to it, as in the first instar. The vasiform orifice is of about the same general form as in the first instar. The lingula is spatulate with two pairs of side lobes and one terminal lobe. On each side of the terminal lobe arises a seta or spine about -one-half as long as the entire vasiform orifice. Between the two pairs of side lobes on each side a smaller spine arises. The upper surface of the lingula bears longitudinal rows of minute setæ, as in the previous instar. When in its natural position, the lingula reaches nearly to the apex of the orifice. The chitinous ridges which bound the orifice laterally do not meet behind, though the intervening space between them is comparatively smaller than in the previous instar. The eyes are 
proportionally smaller than before, and are now situated internally, instead of at the surface, as in the first instar. The eyes on each side are about on a line with and ontside of the two dorsal spines which have been mentioned ats present on the cephalic region. The vestigial legs and antenna can be distinctly seen, their relative position being as before. The antenne are directed directly backward, reaching a little over one-half the distance to the base of the fore legs. They are thick at the base, narrowing toward the apex, covered with numerous minute papillæ. Their segmentation is indistinct, sometimes two and sometimes three segments being evident. They are immovable in this as well as the following immature stages. The legs are short, similar to a truncated cone in form, transversely wrinkled, with no distinct segments, terminating in a rounded knob, which, perhaps, functions as an adhesive disc. A few minute spines occur near the bases of all three pairs of legs. The mouth-parts are as before. The pair of spines at the anterior margin of the prostomial plate is wanting in this instar, but the pair on the ventral surface under the operculum is present as in the first instar. The colour remains as in the first instar. The length varies from .4 $\mathrm{I}$ to $.4 .5 \mathrm{~mm}$; the greatest width, from .22 to $.26 \mathrm{~mm}$.

The second moult takes place in from four to five days after the first. Third Instar.

In this instar the form, marginal and dorsal spines, marginal wax secretion, rudimentary legs, ventral spines, eyes and colour of the body are as in the second instar. The vasiform orifice is longer than wide. in form resembling a triangle with rounded corners. Operculum nearly semicircular, reaching about one-half the distance to the apex of the orifice. Lingula essentially as in the second instar. The antennæ arise nearer to the bases of the fore legs than in previous instars. They are indistinctly segmented, thick at the base, tapering toward the tip, the basal two-thirds of each is directed directiy inward toward the antenna of the opposite side, while the apical third is bent backward toward the base, the whole forming a figure not unlike the letter $\mathrm{J}$. $.38 \mathrm{~mm}$

The length varies from .56 to $.62 \mathrm{~mm}$; t the greatest width, from .32 to

The third moult takes place in about five or six days after the second. Plup * (Fig. 4).

The form of the pupa is broadly elliptical, the margin finely

"As is customary in describing species of this genus, the specific characters are derived from the pupa. The description of this stage is therefore made complete in itself, and is sufficient to distinguish this from all other described species. 
crenulate; when freshly moulted, flat and thin, without wax secretions. The bodies of the mature pupe appear to be raised from the surface of the leaf by a vertical wax fringe, the height of the body then being about one-third of the width. The dorsum is rugose and nearly flat. There are two pairs of marginal spines: the first pair occurs on the caudo-lateral margin, and the second pair on the caudal margin. The second pair in length is between one-tenth and one-eighth the length of the body, and the first pair less than one-fourth the length of the second pair. 'These last are readily seen by ciearing the pupa in xylol and mounting in xylol balsam, or by boiling the pupa-case in $\mathrm{KOH}$ and mounting in glycerine. The second pair cirve upward and backward, diverging at the base, usually converging posteriorly. There are three pairs of minute dorsal spines as in the previous instars : the first pair is on the cephalic region; the second pair, one on each side of the first abdominal segment; and the third pair one on each side opposite the operculum of the vasiform orifice. Of the three pairs, the third pair is slightly the largest. The segmentation of the abdomen is fairly distinct in the middle; that of the thorax less so. The vasiform orifice is longer than broat, in form similar to a triangle with rounded corners. The orifice is bounded laterally by chitinous ridges, which unite posteriorly, thus differing from previous instars. The operculum is hemielliptical (in the form of an ellipse cut through its shortest axis), reaching from the anterior margin of vasiform orifice to a little over one-half the distance toward the apex. The lingula has one apical lobe and three pairs of side lobes, and is densely covered with longitudinal rows of minute setæ. From the sides of the apical lobe from below arise two spines, one on each side, which extend caudad beyond the apex of the orifice, their length being a little less than one-half the greatest width of the operculum. A second pair, less than one-fifth as long as these, arises one on each side between the first and second side lobes. The anterior pair of side lobes is frequently hidden by the operculum. A shallow furrow extends caudad from the apex of the orifice to the margin of the body.

There is no lateral wax fringe in this instar. The dorsal wax secretion consists of a double submarginal series of glassy waxen rods. The rods of the inner series are never farther away from those of the outer series than the width of their bases. The outer series consists of from about sixty to one hundred (sixty-six to ninety-eight are the limits actually observed) rods of variable length, some being very short, while others are 
three-quarters the width of the body in length. In mature pupæ the rods of the inner are usually longer than those of the outer series. These (the inner series) are usually directed upward, and curve inward over the dorsum of the body. Their length varies, rarely exceeding the width of the body. The rods of the inner series usually alternate with from two to five rods of the outer series, the average number of rods in the inner series being about twenty. Irregularities in the position of the wax rods are frequent ; in fact, no two pupa are exactly alike in this respect, but of the hundreds examined none have been found to arise farther mesad from the outer series than the width of their bases.

On the venter the legs are indistinct, most readily seen in specimens which have recently moulted. Each is short and thick like a truncated cone, with a rounded disc or $\mathrm{knob}$ at the tip. They are transversely wrinkled, and bear minute spines as in the two previous instars, and their relative position remains mohanged. The rostrum (a conical, fleshy papilla, from the apex of which the mouth setze protrude) is situated on the middle line of the body, about one-third the distance from the cephalic to the caudal margin, and nearly equidistant from the bases of the four anterior legs. The antennæ now lie partly hidden in pockets situated one on each side, just outside of the anterior pair of legs. They are directed backward, and are straight, conical in form, the diameter of the base being about one-half the length. They appear to be transversely wrinkled near their apex; no other signs of segmentation are visible. There is a pair of spines situated on the ventral surface, one on each side, below the operculum of the vasiform orifice, as in previous instars.

Colour: greenish yellow; empty pupa-cases white. Internal organs in the basal abdominal region, one on each side, give to this part of the body a bright yellow colour, as in previous instars. No eyes can be distinguished when freshly moulted, but as the pupa matures, the imaginal eyes appear as two brownish spots in tne cephalic region.

The length varies from .748 to $.88 \mathrm{~mm}$.; the greatest width, from .407 to $.54 \mathrm{~mm}$.

The imagoes appear in from twelve to sixteen days. Thus, the time which the insect spends in the immature stages, including the egg, is from four to five weeks.

Adult.

9. The length of the body of the adult female varies from I. 5 to I.20 $\mathrm{mm}$. The colour of head and thorax is pale yellowish buff; 
abdomen pale lemon yellow; tip of rostrum black; legs, rostrum, except the tip, and the antennæ, are of same colour as head and thorax. The whole body, including appendages, is covered with a white, flour-like substance, which is absent at the time of emergence from the pupa-case, but appears in the course of an hour or two. This substance, presumably waxy, is soluble in ether and xylol, but insoluble in alcohol and water. The eyes are completely divided into an upper and a lower pair, both of which are reddish brown in colour. The upper pair is smaller and composed of smaller-sized facets than the lower pair. The antenna consist of seven segments : first segment short and stout ; second segment three times as long as the first, club-shaped, stout, with a few slender spines near the apex; third segment over twice the length of the second, and more slender; segment four about one-fourth the length of the third and narrower than it, cylindrical at the base, slightly cnlarged at the tip segment five one-half as long again as four, of the same form, but more elongate; segment six slightly shorter than five, but longer than four, club-shaped, more slender; segment seven is slightly shorter than six, spindle-shaped, with a small spine arising from a tubercle situated a little beyond the middle, and another smaller spine arising from the tip of the segment. All the segments of the antonnx, except the first two and the tip of the last, are ringed with chitinous ridges. The hind femur is about two-thirds the length of the tibia, the tarsus is about one-third the length of the tibia, and the second tarsal segment is about two-thirds the length of the first tarsal segment. Average length of the hind femur about $.275 \mathrm{~mm}$.; of the tibia, about $.3^{8} \mathrm{~mm}$. The trochanters of the posterior pair of legs are deeply grooved on the caudal side, and at the bottom of the cavity thus formed arises a single stout spine, which is directed upward and outward. The vasiform orifice is subcircular in outline. The operculum is concave on its caudal margin, and covers the anterior half of the orifice. The lingula is protruding, setose, gradually enlarging distally, and squarely truncate at caudal end. The fore and hind wings are each provided with a single unbranched median vein. The margin of the wings is beaded all round, each bead consisting of a minute globule, from the outer side of which two or three minute setæ arise. The length of the fore wings is about $\mathrm{I} \mathrm{mm}$; width, about $.5 \mathrm{~mm}$. The rostrum is three-jointed. Ovipositor ordinary, usually bent upwards when not in use.

5. Average length about $.90 \mathrm{~mm}$. Proportionately smaller than female, otherwise differs only in the sexual organs. 
I have named this insect in honour of Dr. A. S. Packard, who first called attention to its occurrence on strawberry plants at Amherst, Mass.

All stages described from numerous specimens. Types of pupæ and adults deposited in the collection of the Massachusetts Agricultura! College.

Bibliography.

Aleurodes vaporarium, Pack. Am. Nat., Vol. IV., p. 686 ( 187 I).

Aleurodes vaporarium, Pack. Guide, p. 7 I 2 (I883).

Aleurodes vaporarilim (?), Garman. Ann. Rept. Ky. Exp. Sta,, p. 37 (1890).

Aleurodes vaporarium (?), Garman. Agric. Science, Vol. V., p. 264, (1891).

Aleyrodes, sp. (?), Riley. Insect Life, Vol. II., p. I 7, (I892).

Aleurodes sp. (?), Webster. Ann. Rept. Ohio Fixp. Sta., p. xxxv. (1894).

Aleyrodes vaporariorum, Britton. Igth Rept. Conn. Exp. Sta., p. 203 (1896). (r $90 \mathrm{I})$

Aleyrodes sp. (?), Slingerland. Bul. 19, Cornell Exp. Sta., p. I 55

Aleyrodes vaporariorum (?), Britton. Bul. i 40, Conn. Exp. Sta, pp. $3,10,14,17$ (1902).

Explanation of Plate 2.

(All Figs. greatly enlarged.)

Fig. I - Egg.

Fig. 2.- First instar.

Fig. 3.-Right hind leg, first instar.

Fig. 4,--Dorsum of the pupa.

\section{AN ACKNOWLEDGMENT.}

I desire, on behalf of the Entomological Society of Ontario, to publicly acknowledge its indebtedness to Mr. H. Bird, Rye, N. Y., for a series of recently-bred specimens of Hydrecia, and his magnanimous liberality in so freely parting with such rare species for its benefit, that cost hirn so much patient labour, valuable time and industrious research to secure. The expertness he has attained in discovering the food-plants and obscure breeding habits of this difficult genus is remarkable; whilst the perfection of scale and colour in the specimens that leave his hands is indescribable, and must be seen to be fully realized.

$$
\text { J. Alston Moffat, Curator. }
$$

